\title{
PRINCIPAL NEW ZEALAND EARTHQUAKES IN 1982
}

\section{Warwick D. Smith*}

No earthquake in New Zealand in 1982 reached magnitude 6 , but there were a number over magnitude 5 , the largest of which was the September 3 shock in Hawke's Bay which registered 5.8. Portable equipment was installed in the area, and recorded many aftershocks about $50 \mathrm{~km}$ deep beneath the city of Hastings. It is assumed, therefore, that this was the location of the main shock, and this depth, rather greater than usual for that part of the country, explains the lack of high intensities. The Earthquake and War Damage Commission has received more than 400 claims, all minor. The maximum intensity was MM VI. Any damage to buildings was only superficial.

Power to the city of Gisborne was put out by an earthquake of magnitude 5 on March 3. Another of similar magnitude occurred near Masterton on February 6 , and was felt from Hawke's Bay to Wanganui and Wellington.

A swarm of earthquakes which occurred just to the south of Wanganui was much over-rated by the news media. The largest was of magnitude 5.2, on October 14, and two others reached 5.0. Some initial reports of damage appear to have been unfounded, although there was indeed some minor damage in the city, with intensities about MM VI. The epicentre was some $20 \mathrm{~km}$ to the south of Wanganui in the South Taranaki Bight. Portable recording equipment was installed within the first two days, and records of more than two hundred small earthquakes were obtained. The epicentres of these earthquakes were indistinguishable from one another, indicating a seismic source of extremely limited extent. The unusual character of the seismograms made at the portable stations, very consistent from one earthquake to another, has allowed inferences to be made about the crustal structure in the area.

Given the possibility that the swarm of earthquakes might be a foreshock sequence, and in the hope of obtaining strong motion records of a large event, should it occur, strong motion recorders were installed in the Wanganui area by the Physics and Engineering Laboratory and the University of Canterbury, each organisation providing two instruments. A large event did not occur, and these instruments were eventually moved back to their permanent locations. The exercise, nevertheless, was a useful one. The benefit could have been huge, and I suggest that instruments could be similarly deployed in future, in similar circumstances.

Public attention was aroused in May, when a swarm of very small earthquakes occurred near Rotorua. As is usual in the thermal and volcanic area, these earthquakes were very shallow, with focal depths probably less than five kilometres. Intensities were therefore much higher (MMV-VI) than would normally be expected from a swarm whose largest magnitude was 2.5 .

New Zealand is a region of deep earthquakes, as well as shallow ones, and of these there were several which reached magnitude 5 , under South Taranaki on August 8, October 12 and October 30 , and one to the wast of Lake Wanaka and $150 \mathrm{~km}$ deep, on July 5. A shallow earthquake of magnitude 5 occurred about $100 \mathrm{~km}$ off the Wairarapa coast on June 16, followed by many small aftershocks. None of these posed any threat, but they are important scientifically. Of interest also was the small earthquake (magnitude 4.2) which occurred to the south of Dunedin, just offshore, on June 23. It is possible that this shock, in a relatively quiet area, could have been associated with the Akatore fault, which is the subject of a current study by University of Otago geologists.

* Seismological Observatory, DSIR, Wellington 